Transportation Research Forum

International Airports: Economies of Scale and Marginal Costs

Author(s): Juan Carlos Martín and Augusto Voltes-Dorta

Source: Journal of the Transportation Research Forum, Vol. 47, No. 1 (Spring 2008), pp. 5-22

Published by: Transportation Research Forum

Stable URL: http://www.trforum.org/journal

The Transportation Research Forum, founded in 1958, is an independent, nonprofit organization of transportation professionals who conduct, use, and benefit from research. Its purpose is to provide an impartial meeting ground for carriers, shippers, government officials, consultants, university researchers, suppliers, and others seeking exchange of information and ideas related to both passenger and freight transportation. More information on the Transportation Research Forum can be found on the Web at www.trforum.org. 


\title{
International Airports: Economies of Scale and Marginal Costs
}

\author{
by Juan Carlos Martín and Augusto Voltes-Dorta
}

Regarding some regulation fields, such as optimal investments and pricing policies, marginal cost estimations for infrastructure-intensive transport services is always a challenging task. The lack of comparable data among airports is one of the causes which could explain the relative scarcity of this literature in the past. In this paper, the returns to scale and marginal costs are estimated using single-and multi-product translog specifications of a long-run cost function. A pooled database of financial data on 41 airports across Europe, North America, Asia, and Australia for the period 1991-2005 was used. Significant economies of scale and little degree of technological progress are found using Work Load Units (WLU) and Air Traffic Movements (ATM) as output measures. Additionally, individual long-run marginal cost estimates are provided for each output measure, and for every airport under study.

\section{INTRODUCTION}

Transport activities have been usually considered in the past as public services. Thus, authorities and regulators have examined different issues regarding efficiency, optimal investments, first best pricing policies, and market structure. In the airport industry, the choice of any pricing policy provokes a direct effect on demand and congestion, and if prices are not optimally set, false market signals could misguide dynamic decisions about optimal capacity investments. Charging for the use of transport infrastructures is a central issue in European Transport Policy, which supports a pricing scheme based on social marginal costs. In such sense, the estimation of cost functions appears to be a suitable solution that will gain momentum in the near future to study market structure and economies of scale.

Airports have become increasingly important assets to foster and guarantee adequate economic growth of the regions they serve. For this reason, studies of airport market structure and performance are becoming increasingly important for policymakers and regional planners of surrounding metropolitan areas. The use of airports has increased in recent years in spite of the appearance of important drawbacks such as the 9/11 terrorist attack, the Severe Acute Respiratory Syndrome (SARS), and the trend of continuous expansion in air traffic and freight that does not seem to stop. Thus, most of the important airports of the world suffer from severe congestion and appropriate expansion programs have become urgent.

In this environment, airport cost efficiency and adequate revenue generation to cover costs are among the critical issues that airport managers need to continually consider. There is a huge panoply of investment programs which compete in the public budget, and airport financing is a key factor for successful operation of an airport because a new regulatory environment precludes airports from obtaining public subsidies in most of the cases. So, new financing engineering practices have evolved in order to accomplish new investments minimizing the capital costs. On the revenue side, airport pricing policies are not only influenced by economic factors but also by social and political objectives.

Given the need for better understanding of airport performance, especially for those airports which are publicly funded, the study of airport cost functions is paramount regarding this topic. After the new trend to airport privatization, market power of these units and information about airport costs played a central role in determining optimal charges. Regulators need to re-examine the necessity of public pricing policies with respect to airports. Studies of marginal costs and economies 
of scale are central issues as researchers try to find out whether airports are structurally more like natural monopolies or can sustain healthy competition.

So, the aggregate airport industry is considered as a cost-minimizing homogenous economic unit and the cost structure of the industry is analyzed using different functional forms. Alternatively, a flexible functional form could have been specified to provide some approximation to the true airport production function. However, in this paper the cost function approach has been chosen to estimate on grounds that input prices are exogenous but input quantities are endogenous to airports. Grounded on the duality properties between the cost and production functions, it is unlikely that any useful information is lost by using the cost function instead of the production function.

According to Doganis (1992) there is empirical evidence that there are economies of scale in airport operations. However, when the airport has just expanded its capacity, unit-operating costs initially tend to increase. The previous literature of airport costs is not as extensive as in other transport modes. This paper extends the previous work, in particular by including a longer period of time and a multi-output approach including two different outputs. However, in order to estimate the marginal costs for landings, additional information regarding the different types of aircraft would have been preferable, since it is likely that the marginal costs of landings depend on this. Therefore, this paper focuses on passenger costs. It should be noted that the available data on passenger costs is also very limited, and more detailed information would have been desirable.

The rest of the paper is organized as follows. The next section develops the econometric issues of the model. A brief literature review on the estimation of cost functions in the airport industry is discussed in the following section. Some methodological notes are discussed in the next section. The models and results of the case study are presented in the succeeding section, and the last section summarizes the major findings of this study.

\section{LITERATURE REVIEW}

The identification of scale economies from production or cost functions, as previously mentioned, is a basic tool in order to adequately regulate an industry. Jeong (2005) shows that only a few studies have dealt with the costs of airport infrastructure services, and that the use of very different data and methodologies provides inconsistent findings, mainly related to: 1) major limitations about capital costs and input levels; 2) a partial view of the airport activity, especially while dealing with the output definition; and 3) the difficulty in collecting comparable data across different airport size and location.

Keeler (1970) used ordinary least squares models (OLS) to estimate two Cobb-Douglas partial cost functions ${ }^{1}$ for both capital and operating costs, using air transport movements (ATM) as output. He found constant returns to scale (CRS) in airport operations using pooled time series and cross sectional data from 13 U.S. airports between 1965 and 1966. Doganis and Thompson $(1973,1974)$ also estimated Cobb-Douglas ${ }^{2}$ models separating both capital and operating costs. They used work load units $(\mathrm{WLU})^{3}$ as the output variable. The definition of WLU is based in the composite measure that is equivalent to one passenger or $100 \mathrm{~kg}$ of cargo. They found increasing returns to scale (IRS) up to three million WLU using cross sectional data from 18 British Airports for 1969. However, both studies are limited by a very small database and its partial rather than total approach.

Tolofari et al. (1990) used a pooled cross section-time series data for seven airports of the British Airport Authority (BAA) for 1979-87 to model a short-run total cost (SRTC) function with fixed capital stock. They were the first authors adopting the translog function, whose variables were output (WLU), the input prices of labor, equipment, and residual factors, capital stock, passengers (PAX) per aircraft traffic movement (ATM), percentage of international passengers, percentage of terminal capacity used, and a time trend. Using SURE estimators, they found that there were IRS up to 20.3 million WLU. While it was a significant finding, it could not be easily generalized because only one airport in the sample (Heathrow) served more than 20 million WLU. 
Rendeiro (2002) estimated a translog total cost function, using WLU as the output measure and considering capital and labor costs, using a pool of data of 40 Spanish airports for 1996-1997. Main et al. (2003) constructed four Cobb-Douglas models, using WLU or PAX as output, and including depreciation or not. Other variables were price of staff, price of other costs, passengers divided by air transport movements, the percentage of passengers classified as international, and total assets. The price of staff was estimated by dividing staff costs by the number of full-time equivalent employees. Prices of 'other costs' were estimated as expenditure on other costs divided by the value of tangible assets. They found IRS up to five million WLU or four million PAX, using a dataset of 27 airports in the United Kingdom for 1988 and another dataset of 44 airports from around the world between 1998 and 2000.

In order to examine economies of output scale under the given state of capital infrastructure and facilities, Jeong (2005) estimated a translog specification for total operating costs, using three different output definitions: Passengers, WLU, or an output index. Additionally, he used a similar aggregated input index (excluding capital costs) and a cost-of-living index as a proxy for the factor price $^{4}$. This study found that economies of output scale in the airport industry were present up to 2.5 million PAX or three million WLU, using a cross-sectional database from 94 U.S. airports for 2003.

Regarding infrastructure pricing, Morrison (1983) estimated various cost functions in order to compute optimal long-run toll costs. He estimated the marginal maintenance, operations and administrative costs of airports to be \$12.34 (1976 dollars) per ATM. Link et al. (2006) specified a Seasonal Auto Regressive Moving Average (SARMA) model to identify a relationship between the number of scheduled person-hours in the service area and the traffic measured as ATM. They reported an estimation of the marginal cost (MC) for an extra ATM of $€$ 22.60. However, for international departures this MC ranges between $€ 25$ and $€ 72 .{ }^{5}$

Oum and Yu (2004) discussed a survey of different airport performance measures and methodologies that have been developed and applied using different outputs, inputs, and methodologies. However, in this study, a neo-classical approach is followed assuming that all the airports are efficient.

In summary, two basic approaches have been used to estimate cost functions: the Cobb-Douglas and translog models. Different variables have been proposed to characterize the activity of airports, but WLU is used in all the cases to measure output activity. Capital costs are included when the researchers study the long-run perspective. This paper extends the previous literature by estimating a multi-output cost function including air traffic movements as well as work load units. Thus, as airports provide a wide range of services and facilities to passengers and airlines, this topic is better addressed considering the multi-output nature of airports.

\section{THE ECONOMETRIC ESTIMATION OF COST FUNCTIONS}

In those industries in which firms are price takers in input markets, the multi-product cost function is defined as the minimum expenditure incurred by the firm to produce the output $Y$ at input prices $\omega$, given some technological constraints:

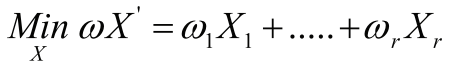

$$
\text { s. t. } F(X, Y) \geq 0
$$

$X$ : vector of conditional input demands.

$Y$ : output vector.

$\omega$ : vector of input prices. 
The solution of this problem is represented by the vector of conditional input demands $X^{*}=X^{*}(\omega, Y)$. Thus the cost function $(C(\omega, Y))$ is obtained by replacing $X^{*}$ in the previous objective function. This is usually known as the long-run cost function, that means that all inputs may vary in the time period considered. If some inputs are restricted to be fixed, then the short-run cost function $C\left(\omega_{v}, Y, \bar{X}\right)$ could be also obtained by only considering variable input prices.

The estimation of $C$ requires observations on costs, outputs, and input prices associated to firms whose behavior is assumed to be cost-minimizing. Some functional form has to be postulated in the stochastic specification of the cost function, namely

(2) $C=H(\omega, Y)+\varepsilon$

Where $C, \omega$ and $Y$ are observed variables and $\varepsilon$ is the error term. The function $H$ is explicitly formulated through unknown parameters reflecting some type of relationship between $C$ and the independent variables. The estimation of these parameters is the objective of the econometric process.

\section{The Model Specification and Its Estimation}

Duality ensures that, under certain regularity conditions, ${ }^{6}$ the specification of $C$ may be interpreted as the total cost function of some underlying production function or technology, even though it is not always possible to express it explicitly. Diewert (1971) showed that it is possible to make very general specifications of $C$ while maintaining all classical restrictions on the underlying structure of production. Thus, it is desirable to specify a functional form which is flexible (i.e., prior restrictions are not imposed on its first and second order derivatives). Of all the functional forms tested over the last 30 years, the transcendental logarithmic "translog" (Christensen et al. 1973) is one of the most popular and has been applied extensively in the past. It provides a local second order approximation to any cost structure and allows a great variety of substitution patterns. Linear homogeneity can also be imposed by including certain linear restrictions to the parameters, which also reduce significantly the number of them to estimate. It presents this general structure, with logged variables.

$$
\begin{aligned}
& \text { (3) } \ln C=\alpha_{o}+\sum_{i} \alpha_{i} \ln y_{i}+\sum_{k} \beta_{k} \ln w_{k}+\sum_{i} \sum_{k} \gamma_{i k} \ln y_{i} \ln w_{k}+\cdots \\
& +\frac{1}{2}\left[\sum_{k} \sum_{l} \delta_{k l} \ln w_{k} \ln w_{l}+\sum_{i} \sum_{j} \rho_{i j} \ln y_{i} \ln y_{j}\right]+\varepsilon \\
& C \text { : Total cost. } \\
& y: \text { output vector: } y=\left[y_{i}, y_{j}, \ldots\right] \\
& w: \text { vector of input prices: } w=\left[w_{k}, w_{l}, \ldots\right] \\
& \alpha_{o}, \alpha_{i}, \beta_{k}, \gamma_{i k}, \delta_{k l}, \rho_{i j}: \text { parameters of the cost function }
\end{aligned}
$$

As output values enter in logarithmic form, the translog does not have a finite representation if any output has a zero value. However, this can be solved by estimating the equation using a generalized translog (that is, a translog with a Box-Cox transformation for outputs), or some other form such as Röller's quadratic-CES form. This procedure allows a simple calculation of outputs' cost elasticities $\left(\alpha_{i}\right)$ and the Hessian values $\left(\rho_{i j}\right)$, which are parameters to be estimated by the model and represent the first and second order derivatives of the logarithm of the total cost function with respect to each output component. These parameters are essential in identifying mean economies of scale (S) (JaraDíaz 1983).

$$
\left.\frac{\partial \ln C(w, y)}{\partial \ln y_{i}}\right|_{\bar{y} \bar{w}}=\alpha_{i}+\sum_{j=1} \rho_{i j} \ln \left(y_{j}\right)+\left.\sum_{k=1} \gamma_{i k} \ln \left(w_{k}\right)\right|_{\bar{y} \bar{w}}=\alpha_{i}
$$


(5)

$$
S=\frac{C(w, y)}{\sum_{i} \frac{\partial C(w, y)}{\partial y_{i}} y_{i}}=\frac{1}{\sum_{i} \alpha_{i}}
$$

The translog cost equation is linear in parameters and can be estimated using classical least squares regression techniques upon making the necessary assumptions about the applicable stochastic error terms, Nevertheless, the translog function is commonly estimated jointly with the cost minimizing input cost share equations by means of a seemingly unrelated equation (SUR) regression (Zellner 1962) and using maximum likelihood estimators. Cost minimizing factor shares $S_{i}$ can be obtained by applying Shephard's lemma. This procedure allows researchers to include $(r-1)$ additional equations to the cost function where $r$ is the number of inputs ${ }^{7}$ that have been considered in the model specification. As no additional parameters are included, the estimation becomes more efficient.

$$
s_{i}=\frac{w_{k} X_{k}}{C}=\frac{\partial C}{\partial w_{k}} \frac{w_{k}}{C}=\frac{\partial \ln C}{\partial \ln w_{k}}=\beta_{i}+\sum_{l=1} \delta_{k l} \ln w_{l}+\sum_{i=1} \gamma_{i k} \ln y_{i}
$$

Additionally, for panel data, it would be also interesting to account for technological change and technological bias in order to test Hicks' neutrality (Stevenson 1980). ${ }^{8}$ Therefore, as the data support all new parameters to be estimated, time $(\mathrm{t})$ is incorporated into the model by a truncated third-order specification.

\section{SOME METHODOLOGICAL NOTES}

\section{The Definition of Output}

An airport's primary function is to provide an interface between aircraft and the passengers or freight (Doganis 1992). Therefore, an analysis of output requires, at a least level, data of passengers and ATMs. From this very simple perspective, the output of an airport could be composed of: 1) ATMs, according to Link and Nilsson (2005), considering traffic volumes leads to a problem of output separation, as vehicles have a different impact on infrastructure damage. Regarding aircraft, a welldefined separation criterion should be the weight of the aircraft, i.e., between wide and narrow body. ${ }^{9}$ However, neither an aircraft's origins nor destinations are to be considered as long as different costs are not involved regarding the airport infrastructure. Additionally, according to what many pricing policies suggest, every output has to be subject to peak and off-peak congestion considerations; ${ }^{10}$ 2) The passengers/baggage flow systems may impose very different costs depending primarily on the composition of different origins and destinations, and also on peak considerations; 3) The cargo is mainly measured in tons of freight and mail, and the same consideration applied to passengers and baggage flows can also be valid for this item; 4) The commercial revenues are beginning to be a more important source of revenues in the perimeter area of an airport. This includes different rental concessions like restaurants, rental cars, parking space and others; and 5) the noise level or other important environmental cost measured in the vicinity area. This issue is beginning to be more important in the calculus of social marginal cost in which all the externalities need to be internalized.

However, in practice, the lack of adequate data obliges researchers to estimate only marginal costs for one or two outputs at most: ATMs and WLUs, respectively. Multi-output definition is usually constrained by data sources, and degrees of freedom shrink exponentially with the consideration of a small number of products. Additionally, the specification of many variables which are highly correlated such as ATMs and passengers could also lead to some multicolinearity problems, and nonefficient estimators may hinder the structural analysis which can be done. Hence, the previous literature has been primarily focused on single product estimations, using aggregate measures such 
International Airports

as WLU, which is a very limited approximation to the very complex aspects of airport productivity issues

\section{Input Prices}

According to Doganis (1992), labor costs are the most important single cost element. This is due to the fact that handling activities are particularly labor intensive. As this item can also include social and medical benefits, labor costs produce some additional heterogeneity because they are subject to very different region's social policies. Current methodology starts with labor expenses in the airport operator accounts, and prices are obtained by dividing its figure by the full-time equivalent employees (FTEE). However, a main limitation that frequently appears is related to outsourcing practices, which can put labor expenses into the materials and other expense category. So, it is really important to adjust the data according to the different activities in which airports are actually involved. Additionally, some third party firms are really involved in transportation core activities, but their costs cannot be included in the consolidated annual balances of airports. Airport complexity usually implies a very difficult engineering approach in order to compare the airport's performance.

The second major cost element is capital costs, which normally encompass interest paid and economic depreciation. Also, especially regarding land requirements for runways and other major facilities, some measure of opportunity cost should also be incorporated. However, this last value is not found in financial accounts, and a methodology for its proper valuation at an international scale using some homogeneous criteria would deserve special attention in the international forums such as International Air Transport Association (IATA) or International Civil Aviation Organization (ICAO). As known, book values are very different than economic values, and interest payments do not represent the true opportunity costs (Oum and Waters 1996). Additionally, it is a major challenge to accurately value capital assets and collect consistent and comparable information on capital expenditures because: 1) investments over many years may be "hidden" in the published figures; 2) facilities at airports may be built and operated by airlines or other enterprises (U.S. airports); 3) some financing sources may not appear in the airport accounts, especially governmental aid, whose related assets may not be charged at a depreciation cost; 4) taxation, interest rates, and accounting practices are also heterogeneous.

Thus, practitioners have used a very pragmatic approach in collecting depreciation and interest figures from accounting official books, and calculating prices according to some ratio of these figures over an output measure (e.g., WLU or ATM). This approach has been commonly used in the previous empirical exercises. The last alternative is to estimate short-run total cost functions (SRTC) given a fixed (or quasi-fixed) capital stock, and use this estimation to derive the long-run cost function by minimizing SRTC with respect to the fixed factor.

Other operating costs, under the label of "Materials and OS Work" include "the cost of spare parts and consumables that the airport actually expends in providing facilities or services i.e. operation and maintenance of fixed assets (not listed as depreciable assets), cost of services, and supplies such as heating, air conditioning, cleaning, laundry, sanitation." (ICAO 2006). This amount greatly depends on the concession contracts (in outsourcing cases). In this case, prices are usually obtained by dividing total costs of the activities which are outsourced by an output indicator, or using some proxy price such as energy or water as a representative price of this component.

Additional factors to account for could be the passengers' time as a very important input for every transport activity. This generalized cost approach has inspired some marginal cost estimations which have been cited above. Finally, the consideration of noise as an output would also require considering the silence of the surrounding communities as an input, and the externalities of the noise should be evaluated according to some methodology, but such a problem lies for the moment out of the scope of this research. 


\section{INTERNATIONAL AIRPORTS}

Availability of good financial data on European airports is very restricted, and it is difficult to find a unique source to gather all the necessary information to estimate cost functions. In fact, many different sources have been used. For other than U.S. airports, financial data has been directly obtained from the airports' published annual reports or financial statements. In most cases, airports' websites include enough detailed information of traffic activity, such as, ATMs, passenger enplanements, and cargo. However, some official statistics of governmental offices were also consulted, especially foreign trade records. In other cases, airport authorities have been contacted in order to fill the gaps of information in the database.

The figures for the U.S. airports were obtained from the CATS financial database provided online by the Federal Aviation Administration (FAA 2006). The CATS reporting program provides both a balance sheet and income statement for any airport operating under the FAA regulations. The number of full-time equivalent employees was obtained either from airports' websites or by direct request. The traffic figures were obtained from the ICAO / ATI Airport Traffic Summary reports (ICAO 2004), which provide data for airports around the world between 1992 and 2004. Operational data for 2005 was obtained from the FAA Airport Master Records and further details were available in the 2003 edition of IATA / ACI / ATAG Airport Capacity and Demand profiles (IATA 2003). Other sources were Wikipedia or the Google Earth software.

Data collection has been completed for the following variables: labor, materials, and capital costs (amortization and interest), full-time equivalent employees, and traffic figures: passengers, ATMs, and tons of cargo. An unbalanced pooled database for 41 airports in the EU, US, Canada, Australia and Asia for the period 1991-2005 has been obtained. Airport size ranges from 206,000 (Liege) to 83 million passengers (Atlanta) with the following average figures: 15,970,000 passengers and 216,000 ATMs. Table 1 depicts the airports that have been used in the analysis. Data availability has been the main criterion used to select the sample of the airports. However, an adequate coverage of airports, regarding their size (small vs. large) and location (Europe, America, Asia and Australia), was also important to the selection of the airport sample. All the variables related to costs and prices were converted to 2005 Purchasing Power Parity (PPP) U.S. dollars (USD) using OCDE published indicators. Labor prices were obtained dividing their respective total labor cost by fulltime equivalent employees, and materials and capital prices were obtained by dividing their total expenses by WLUs and ATMs, respectively. It is evident that these input prices should have been obtained by dividing their total expenses by some other proxy variable which reflects more precisely the type of input used in the category. For example, the capital costs could be divided by some multi-lateral input calculated by using the length of runways and the surface of terminal buildings. Regarding the materials price, the amount of subcontracting will impact this input price, as the higher the amount of outsourcing, the higher the materials cost and, thus, the higher the materials input price. However, if all the airports operate efficiently the amount of outsourcing should not vary excessively. So far, the literature has not resolved this important issue and researchers pragmatically divide the total expenses by a measure of output. In fact, material costs include all costs except labor, depreciation, and interest, so it is like an open category which cannot be related to a good proxy which measures its input.

Additionally, in order to provide an easy calculation of output cost-elasticities, explanatory variables ${ }^{11}$ are deviated with respect to their logged average, i.e.

$$
y=\ln (Y)-\ln (\bar{Y})
$$


International Airports

Table 1: International Airports Under Study

\begin{tabular}{|c|c|c|c|c|c|}
\hline Country & Airport & PAX & Country & Airport & PAX \\
\hline Australia & Adelaide & $4,966,321$ & Germany & Dusseldorf & $15,339,886$ \\
\hline Australia & Alice Springs & 610,000 & Germany & Hamburg & $9,896,592$ \\
\hline Australia & Brisbane & $14,059,988$ & Germany & Hanover & $5,173,264$ \\
\hline Australia & Darwin & $1,192,000$ & Germany & Munich Inernational & $26,835,231$ \\
\hline Australia & Perth & $6,038,348$ & Germany & Nuremberg & $3,653,569$ \\
\hline Australia & Sydney & $26,426,363$ & Germany & Paderborn/Lippstadt & 939,483 \\
\hline Austria & Graz & 898,504 & Germany & Stuttgart & $8,831,216$ \\
\hline Austria & Linz & 750,171 & Hong Kong & Hong Kong Intl & $27,748,513$ \\
\hline Austria & Salzburgo & $1,422,397$ & Norway & Oslo & $14,865,460$ \\
\hline Austria & Vienna Intl & $14,882,328$ & Slovenia & Ljubljana & $1,048,238$ \\
\hline Belgium & Liege & 206,986 & Switzerland & Zurich & $17,252,906$ \\
\hline Belgium & National & $15,634,517$ & United Kingdom & Birmingham & $8,796,712$ \\
\hline Canada & Toronto Pearson & $28,615,709$ & United Kingdom & Bournemouth & 493,234 \\
\hline Canada & Vancouver & $15,700,000$ & United Kingdom & Bristol & $4,603,106$ \\
\hline Canada & Calgary & $9,174,039$ & United Kingdom & London Luton & $7,520,467$ \\
\hline Canada & Otawa & $3,609,885$ & United Kingdom & Manchester Intl & $20,970,248$ \\
\hline China & Beijing Capital & $34,897,028$ & United States & Anchorage Intl & $4,881,009$ \\
\hline Croatia & Zagreb & $1,408,206$ & United States & Baltimore/Washington & $20,341,567$ \\
\hline Czech Rep, & Praha & $9,593,633$ & United States & Charlotte & $25,543,734$ \\
\hline Denmark & Billund & $1,849,799$ & United States & Cincinnati/ N. Kentucky & $22,062,557$ \\
\hline Denmark & Copenhagen & $19,034,585$ & United States & Dallas-Ft,Worth & $59,445,740$ \\
\hline Estonia & Tallin Airport & 997,461 & United States & Denver & $42,275,913$ \\
\hline Germany & Bremen & $1,674,977$ & United States & Atlanta Hartsfield & $83,265,471$ \\
\hline Germany & Cologne/Bonn & $8,406,400$ & United States & Chicago O'hare & $75,534,692$ \\
\hline Germany & Dresden & $1,626,248$ & United States & San Francisco Intl & $32,744,186$ \\
\hline Germany & Moenchengladbach & 42,518 & United States & Seattle Intl & $28,799,435$ \\
\hline
\end{tabular}

[PAX is the abbreviation for number of passengers ]

For this case study, a long-run cost function was estimated for two different specifications: single and multiproduct. The well-known translog cost system, which includes cost share equations in order to get more degrees of freedom, has been used. It is evident that some airports are spatially constrained for geographic or political reasons, so the long-run assumption in which all inputs are variable may not hold for these airports. The model has been estimated using the seemingly unrelated regression procedure (SURE) with the method of maximum likelihood. Finally, all marginal cost estimations are easily calculated as follows:

(8) $\frac{\partial C}{\partial y_{i}}=\frac{\partial \ln C}{\partial \ln y_{i}} \frac{C}{y_{i}}$

where $C$ is the total cost and $y_{i}$ is each output respectively. Once every transformation has been done, data suitability is checked by estimating a Cobb-Douglas specification in search of correct signs and regularity conditions. Results are shown in Table 2 . $\left(\mathrm{R}^{2}=0.98\right)$ 
Table 2: Cobb-Douglas Estimation Results

\begin{tabular}{lcccc}
\hline & Coefficient & Std. Error & t-Statistic & Prob. \\
\hline Constant & 11.92377 & 0.008271 & 1441.604 & 0.0000 \\
Atm & 0.475784 & 0.026955 & 17.65130 & 0.0000 \\
Wlu & 0.480817 & 0.024782 & 19.40180 & 0.0000 \\
Capital & 0.389062 & 0.016560 & 23.49348 & 0.0000 \\
Material & 0.532731 & 0.014817 & 35.95342 & 0.0000 \\
Labor & 0.078155 & 0.014050 & 5.562784 & 0.0000 \\
Time & -0.010487 & 0.002472 & -4.242439 & 0.0000 \\
\hline
\end{tabular}

It can be seen that the Cobb-Douglas specification shows a good performance with correct signs and significance of parameters, mild increasing returns to scale (1.047) which has been obtained as the inverse of the sum of the output cost elasticities (parameters of ATM and WLU, respectively), and technological progress $(-0.010)$. Therefore, data seems to fit well into this very restrictive functional form.

Although the Cobb-Douglas cost function has been used by many previous studies and it is consistent with the theory of production and costs, it has some rather restrictive properties. For example, the elasticity of total cost with respect to output is a constant, whether the firm is small or large. If this elasticity is less than unity, then there will be economies of scale for all outputs, and the average cost function will be decreasing for all outputs as well.

In addition, the elasticity of cost with respect to each factor price is also constant. For example, in Table 2, 0.07 represents the elasticity of cost with respect to the labor price. Thus, with the CobbDouglas functional form the total cost will always increase by $0.07 \%$ every time the labor price increases by $1 \%$. Moreover, under the Cobb-Douglas cost structure, the share of expenditures on each factor of production is a constant, regardless of the relative factor prices or the level of output. For example, the share of total costs spent on labor is always $8 \%$. Similarly, the shares of total costs spent on capital and materials are always 39\% and 53\%, respectively. Finally, the elasticity of substitution of one factor for another is always unity under a Cobb-Douglas cost structure.

To sum up, this model is estimated to show that economies of scale are not well represented, and for this reason, the models of previous studies which were based on this specification could calculate the values of the returns to scale erroneously. The next section shows how the specification of translog cost functions presents higher returns to scale.

\section{The Long-Run Single Product Translog Model}

In order to compare the results of this study with those that have been obtained in the previous literature, the translog cost function is proposed including WLU as the single output variable, the prices of capital (WC), materials (WM), and labor (WP), and finally a time variable (T) to study potential technological changes in the period of time which is under analysis. The system is completed with the cost share equations and other common regularity restrictions such as homogeneity of degree one in prices. The EVIEWS software was used to estimate the model with seemingly unrelated regression (SURE) procedure. Estimation results are shown in Table 3. $\left(\mathrm{R}^{2}=0.91\right)$ 
International Airports

Table 3: Single Product Long-Run Cost Function Estimation Results

\begin{tabular}{lcccc}
\hline & Coefficient & Std. Error & t-Statistic & Prob. \\
\hline constant & 11.92354 & 0.021587 & 552.3431 & 0.0000 \\
wlu & 0.713981 & 0.013161 & 54.24999 & 0.0000 \\
capital & 0.333639 & 0.005977 & 55.81654 & 0.0000 \\
material & 0.377507 & 0.006987 & 54.03088 & 0.0000 \\
labor & 0.293305 & 0.005094 & 57.57430 & 0.0000 \\
wlu * capital & 0.010967 & 0.005414 & 2.025629 & 0.0430 \\
wlu * material & 0.036832 & 0.005750 & 6.405586 & 0.0000 \\
wlu * labor & -0.046502 & 0.004806 & -9.676379 & 0.0000 \\
material * capital & -0.069808 & 0.006155 & -11.34200 & 0.0000 \\
material * material & 0.086876 & 0.007656 & 11.34694 & 0.0000 \\
capital * capital & 0.095865 & 0.007997 & 11.98828 & 0.0000 \\
material * labor & -0.010245 & 0.005853 & -1.750279 & 0.0803 \\
capital * labor & -0.028904 & 0.006015 & -4.805660 & 0.0000 \\
labor * labor & 0.031924 & 0.009916 & 3.219382 & 0.0013 \\
wlu * wlu & -0.034353 & 0.016605 & -2.068817 & 0.0387 \\
time & -0.022949 & 0.004844 & -4.737539 & 0.0000 \\
time * capital & 0.008817 & 0.001413 & 6.240803 & 0.0000 \\
time * labor & -0.008804 & 0.001358 & -6.482980 & 0.0000 \\
\hline
\end{tabular}

It can be seen that this specification shows correct signs and that the parameters are significant. Some degree of technological progress is also observed by looking at the value of the time parameter. Additionally, it can be seen that all mathematical assumptions for a proper specification of the total cost function are held (it is increasing in output and input prices). In addition, very important economies of scale in the average airport $(\mathrm{S}=1.40)$ are also obtained by computing the reciprocal of the wlu coefficient. However, this figure seems to be very high, and it gives some idea about the necessity of including a second output measure, which also increases the global signification of the model, as it seems that the variability of total costs is not well explained by a single output. For comparative purposes, the marginal costs for this specification were calculated, which are shown in the fourth column of Table 6, and whose average value is 12.57 US dollars per WLU.

\section{The Long-Run Multiproduct Translog Model}

Using a similar specification as the previous example, the cost function now includes both ATM and WLU as output variables.

Results are presented in Table $4\left(\mathrm{R}^{2}=0.97\right)$. It can be seen that this specification shows a very good performance with correct signs and strong significance of parameters, and, as expected, the global significance of the model measured by $\mathrm{R}^{2}$ has increased. From the values of the two previous parameter estimates, it can be concluded that some degree of technological progress exists for the average airport in the period of time analyzed, and that this technological progress is highly related to labor prices. ${ }^{12}$ 
Table 4: Multiproduct Long-Run Cost Function Estimation Results

\begin{tabular}{|c|c|c|c|c|}
\hline & Coefficient & Std. Error & t-Statistic & Prob. \\
\hline constant & 11.90753 & 0.013456 & 884.9149 & 0.0000 \\
\hline atm & 0.446550 & 0.024829 & 17.98467 & 0.0000 \\
\hline wlu & 0.432750 & 0.019257 & 22.47238 & 0.0000 \\
\hline capital & 0.359618 & 0.003052 & 117.8380 & 0.0000 \\
\hline material & 0.374822 & 0.005298 & 70.74285 & 0.0000 \\
\hline labor & 0.271473 & 0.005411 & 50.17427 & 0.0000 \\
\hline atm * capital & 0.127053 & 0.008644 & 14.69839 & 0.0000 \\
\hline atm * material & -0.161966 & 0.018388 & -8.808232 & 0.0000 \\
\hline atm * labor & 0.059264 & 0.013197 & 4.490628 & 0.0000 \\
\hline wlu * capital & -0.116098 & 0.007438 & -15.60837 & 0.0000 \\
\hline wlu $*$ material & 0.169917 & 0.019724 & 8.614823 & 0.0000 \\
\hline wlu * labor & -0.092171 & 0.011063 & -8.331174 & 0.0000 \\
\hline material $*$ capital & -0.163793 & 0.004967 & -32.97857 & 0.0000 \\
\hline material $*$ material & 0.114709 & 0.025136 & 4.563613 & 0.0000 \\
\hline capital $*$ capital & 0.174501 & 0.005202 & 33.54438 & 0.0000 \\
\hline material $*$ labor & -0.017759 & 0.007197 & -2.467699 & 0.0137 \\
\hline capital $*$ labor & -0.038298 & 0.006480 & -5.910081 & 0.0000 \\
\hline labor * labor & 0.081256 & 0.012719 & 6.388449 & 0.0000 \\
\hline $\operatorname{atm} * \operatorname{atm}$ & -0.113788 & 0.022437 & -5.071506 & 0.0000 \\
\hline wlu * wlu & 0.066817 & 0.016738 & 3.991845 & 0.0001 \\
\hline time & -0.012754 & 0.002640 & -4.830512 & 0.0000 \\
\hline time* labor & -0.004471 & 0.001021 & -4.376858 & 0.0000 \\
\hline
\end{tabular}

The regularity conditions of the cost functions were also checked. The homogeneity condition for the input price vector $(w)$ can be checked using a Wald Test on the sum of the interaction between each output and input price that can be seen below. The Null Hypothesis expressed by the zero values of the sum of the second order parameters is clearly accepted by the Chi-square statistics.

\begin{tabular}{|c|c|}
\hline Null Hypothesis: Homogeneity & $\begin{array}{l}\gamma_{\text {wlu-capital }}+\gamma_{\text {wlu-material }}+\gamma_{\text {wlu-labor }}=0 \\
\gamma_{\text {atm-capital }}+\gamma_{\text {atm-material }}+\gamma_{\text {atm-labor }}=0\end{array}$ \\
\hline Chi-square & Probability \\
\hline
\end{tabular}

Regarding the analysis of economies of scale, the estimation shows that there still exist important increasing returns to scale as the inverse of the sum of output cost elasticities is 1.13 at the mean. ${ }^{13}$ The Wald test on the sum of ATM and WLU first order parameters also shows evidence that the constant returns to scale (CRS) null hypothesis can be rejected.

\begin{tabular}{llll}
\hline Null Hypothesis: CRS & $\alpha_{\text {wlu }}+\alpha_{\text {atm }}=1$ & & \\
\hline Chi-square & 114.1751 & Probability & 0.000000
\end{tabular}

Since the cost function can also be used to describe the technology, the degree of substitutability among the production factors inputs can be analyzed by means of Allen elasticities of substitution. These elasticities are defined as

(9) $\sigma_{A E S i j}=\frac{\lambda_{i j}}{s_{j}}$ where $\lambda_{i j}=\frac{\partial x_{i}}{\partial w_{j}} \frac{w_{j}}{x_{i}}$ and $s_{j}=\frac{w_{j} x_{j}}{C}$ 
Where,

$x_{i}:$ the input demand of input $i$.

$w_{j}$ : the input price of input $j$.

$C$ : Total cost.

$\lambda_{i j}$ : the cross-elasticity of input $i$ with respect to input price $j$.

$s_{j}$ : the input share of input $j$, that is the proportion of total cost spent on input $j$.

Table 5 shows the Allen elasticities of substitution of the production factors considered in the study. When the Allen elasticity is greater than zero, input $i$ is a substitute for input $j$ and the use of input $i$ will increase when the price of factor $j$ increases. If Allen elasticity is negative, input $i$ is a complement for factor $j$ and the use of input $i$ will decrease when the price of the input $j$ increases. If Allen elasticity is zero, price of input $j$ will have no effect on the use of input $i$.

Thus, the estimated Allen elasticities suggest somehow that there exist some possibilities for substitution among the different pairs of production factors, especially materials and labor. There is no evidence that two inputs are complementary as no cross-elasticity is negative. Looking at the own price elasticities, it can be seen that in all the cases the expected negative signs are found, and that demand for labor is by far the most price elastic production factor demand.

Table 5: Allen Elasticities of Substitution Mean (std. dev.)

\begin{tabular}{c|ccc}
\hline & wc & wm & wl \\
\hline \multirow{2}{*}{ Wc } & -0.45978 & 0.04275 & 0.49815 \\
& $(0.350)$ & $(0.5050)$ & $(0.345)$ \\
& 0.04275 & -0.87593 & 0.80000 \\
Wm & $(0.5050)$ & $(0.1857)$ & $(0.666)$ \\
& 0.49815 & 0.80000 & -1.68390 \\
wl & $(0.345)$ & $(0.666)$ & $(0.857)$ \\
\hline
\end{tabular}

The translog cost model is a flexible functional form where elasticities of scale are not constant for each airport, therefore individual estimation for scale elasticities can be calculated (Table 6). It can be seen that: 1) The single product specification consistently overestimates the economies of scale for each airport; and 2) Increasing returns to scale do not seem to be exhausted at any output level in the sample. Even Atlanta Hartsfield presents economies of scale. This result can be easily observed because the estimation of the returns to scale (RTS) is always greater than one. It can also be concluded that the larger economies of scale are present in the larger airports, showing that there is room to reduce the marginal costs, increasing the level of operations in the airport.

Additionally, individual estimates for marginal costs (MC) are also provided in the Table 6 . Figure 1 shows the density kernel plots, ${ }^{14}$ for both WLU and ATM marginal cost estimates, whose means are about 8.47 and 582.04 U.S. dollars, respectively. It can be seen that, as expected, marginal costs for an additional WLU using the multioutput specification are clearly lower than for the single product estimations. So it is necessary to have in mind what type of specification is used when one applies this analysis in order to justify sensible price regulation policies. 
Table 6: Scale Elasticities and Marginal Costs. Individual Airport Estimations

\begin{tabular}{|c|c|c|c|c|c|c|c|}
\hline \multirow[b]{2}{*}{ Country } & \multirow[b]{2}{*}{ Airports } & \multirow[b]{2}{*}{$\operatorname{Pax}\left(10^{6}\right)$} & \multicolumn{2}{|c|}{ Monoproduction } & \multicolumn{3}{|c|}{ Multiproduction } \\
\hline & & & $\begin{array}{l}\text { Returns to } \\
\text { Scale (RTS) }\end{array}$ & $\begin{array}{c}\text { Marginal Cost } \\
\text { WLU }\end{array}$ & $\begin{array}{l}\text { Returns to } \\
\text { Scale (RTS) }\end{array}$ & $\begin{array}{l}\text { Marginal } \\
\text { Cost ATM }\end{array}$ & $\begin{array}{c}\text { Marginal } \\
\text { Cost WLU }\end{array}$ \\
\hline $\mathrm{AU}$ & DARWIN & 1.19 & 1.40 & 13.44 & 1.12 & 280.63 & 7.54 \\
\hline AU & PERTH & 6.04 & 1.51 & 7.62 & 1.10 & 1469.77 & 3.54 \\
\hline $\mathrm{AU}$ & SYDNEY & 26.43 & 1.75 & 10.60 & 1.21 & 2266.07 & 7.81 \\
\hline AT & GRAZ & 0.90 & 1.22 & 18.60 & 1.02 & 635.34 & 8.53 \\
\hline AT & LINZ & 0.75 & 1.22 & 19.53 & 1.01 & 1115.68 & 7.85 \\
\hline AT & SALZBURG & 1.42 & 1.25 & 23.05 & 1.04 & 1199.82 & 11.27 \\
\hline AT & $\begin{array}{l}\text { VIENNA } \\
\text { SCHWECHAT }\end{array}$ & 14.88 & 1.43 & 13.70 & 1.18 & 459.29 & 10.58 \\
\hline $\mathrm{BE}$ & LIEGE & 0.21 & 1.37 & 5.22 & 1.09 & 275.59 & 4.13 \\
\hline $\mathrm{BE}$ & NATIONAL & 15.63 & 1.47 & 8.74 & 1.19 & 447.94 & 5.97 \\
\hline $\mathrm{CA}$ & TORONTO & 28.62 & 1.45 & 15.56 & 1.21 & 676.76 & 10.44 \\
\hline $\mathrm{CN}$ & BEIJING & 34.90 & 1.41 & 18.38 & 1.17 & 1092.98 & 15.12 \\
\hline HR & ZAGREB & 1.41 & 1.18 & 28.95 & 1.02 & 655.61 & 17.96 \\
\hline $\mathrm{CZ}$ & PRAHA & 9.59 & 1.32 & 13.49 & 1.12 & 355.70 & 10.76 \\
\hline DK & BILLUND & 1.85 & 1.29 & 14.48 & 1.07 & 407.62 & 7.85 \\
\hline DK & COPENHAGEN & 19.03 & 1.51 & 6.29 & 1.19 & 376.22 & 3.47 \\
\hline $\mathrm{EE}$ & TALLIN & 1.00 & 1.18 & 24.06 & 1.02 & 541.62 & 11.96 \\
\hline $\mathrm{DE}$ & BREMEN & 1.67 & 1.28 & 16.30 & 1.07 & 511.15 & 7.44 \\
\hline $\mathrm{DE}$ & KÖELN-BONN & 8.41 & 1.40 & 12.00 & 1.14 & 620.44 & 8.51 \\
\hline $\mathrm{DE}$ & DRESDEN & 1.63 & 1.22 & 21.00 & 1.04 & 568.58 & 12.07 \\
\hline $\mathrm{DE}$ & DUSSELDORF & 15.34 & 1.39 & 16.12 & 1.15 & 711.71 & 10.71 \\
\hline $\mathrm{DE}$ & HAMBURG & 9.90 & 1.37 & 13.01 & 1.14 & 367.34 & 10.06 \\
\hline DE & HANOVER & 5.17 & 1.30 & 19.35 & 1.10 & 625.15 & 12.56 \\
\hline DE & MUNICH & 26.84 & 1.41 & 17.58 & 1.20 & 329.44 & 16.23 \\
\hline DE & NUREMBERG & 3.65 & 1.32 & 15.00 & 1.09 & 538.92 & 8.90 \\
\hline DE & $\begin{array}{l}\text { PADERBORN- } \\
\text { LIPPSTADT }\end{array}$ & 0.94 & 1.20 & 26.42 & 1.08 & 135.77 & 20.04 \\
\hline DE & STUTTGART & 8.83 & 1.32 & 19.00 & 1.13 & 403.94 & 14.71 \\
\hline $\mathrm{CN}$ & HONG KONG & 27.75 & 1.59 & 7.56 & 1.18 & 2253.81 & 3.46 \\
\hline NW & OSLO & 14.87 & 1.42 & 10.38 & 1.16 & 539.52 & 6.00 \\
\hline SL & LJUBLJANA & 1.05 & 1.24 & 25.30 & 1.06 & 516.28 & 12.14 \\
\hline $\mathrm{CH}$ & ZURICH & 17.25 & 1.44 & 12.19 & 1.17 & 605.34 & 7.22 \\
\hline UK & BIRMINGHAM & 8.80 & 1.38 & 10.47 & 1.13 & 449.07 & 6.63 \\
\hline UK & LONDON LUTON & 7.52 & 1.34 & 9.87 & 1.11 & 458.44 & 6.57 \\
\hline UK & MANCHESTER & 20.97 & 1.43 & 10.10 & 1.15 & 673.88 & 6.19 \\
\hline US & $\begin{array}{l}\text { BALTIMORE- } \\
\text { WASHINGTON }\end{array}$ & 20.34 & 1.52 & 4.09 & 1.21 & 158.65 & 3.14 \\
\hline US & $\begin{array}{l}\text { DALLAS-FORT } \\
\text { WORTH }\end{array}$ & 59.45 & 1.73 & 2.87 & 1.30 & 168.14 & 1.85 \\
\hline US & DENVER & 42.28 & 1.56 & 8.34 & 1.24 & 483.31 & 4.52 \\
\hline US & $\begin{array}{l}\text { ATLANTA } \\
\text { HARTSFIELD }\end{array}$ & 83.27 & 1.88 & 1.45 & 1.33 & 140.11 & 0.62 \\
\hline US & CHICAGO O'HARE & 75.53 & 1.73 & 4.11 & 1.32 & 248.14 & 2.73 \\
\hline US & SAN FRANCISCO & 32.74 & 1.57 & 10.54 & 1.21 & 1053.86 & 4.19 \\
\hline US & SEATTLE & 28.80 & 1.62 & 4.46 & 1.22 & 372.79 & 1.83 \\
\hline & Mean (USD) & 15.9 & 1.40 & 12.57 & 1.13 & 582.04 & 8.47 \\
\hline
\end{tabular}


International Airports

Figure 1: Marginal Costs Estimations Kernel Densities
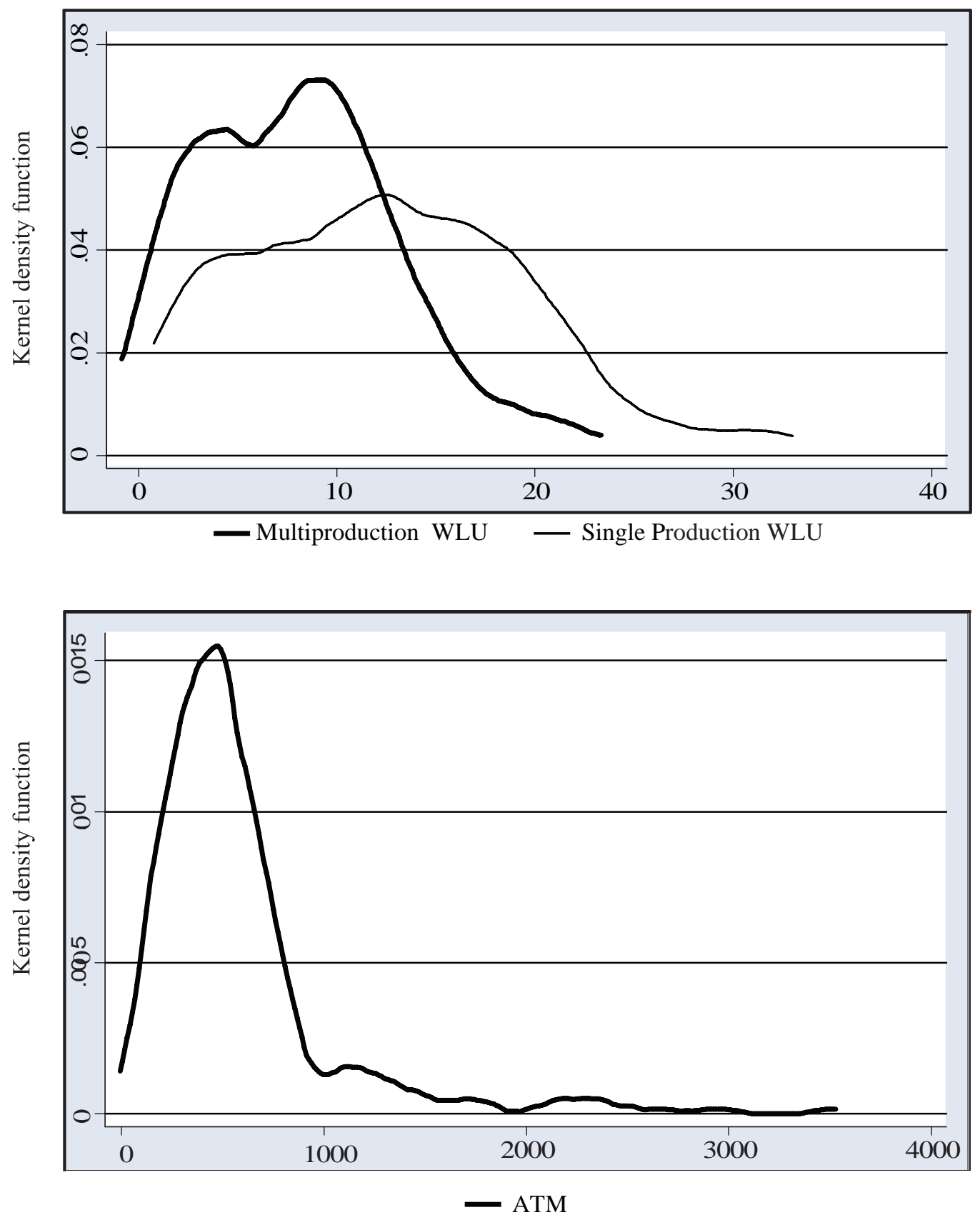


\section{CONCLUSIONS}

Studies of airport costs will continue to be important as new technologies and third party outsourcing firms are becoming more significant and as regulatory reform and privatization of airports are taking place around the world. Different stakeholders, such as airport managers, policymakers and regional planners, must understand costs as they evaluate substantive issues such as the potential savings from multiple airport systems and dedicated terminal operations, the economic costs and benefits of new capacity investments, the sources and measurement of productivity growth and technical change, and the effects of pricing regulations (price caps vs. rate of return). A proper understanding of costs is central to the making of sound airport strategies and the design of sustainable public policy.

A long-run Cobb-Douglas, single-product and multiproduct cost function for airport operations have been estimated using data obtained from a sample of international airports. This paper studies airport operations empirically by providing the estimations of marginal costs, average and individualairport economies of scale. It confirms the advantages of the use of flexible functional forms like the translog model avoiding the misinterpretation of scale economies due to the lack of flexibility of the Cobb-Douglas model. Of course, some of the differences in results between this paper and previous research might be due to differences of airport management goals in different eras or other types of regulatory constraints rather than exclusively to different estimation approaches. The multiproduct approach and the single product analysis is also compared, revealing large differences in productspecific marginal costs when both methods are considered.

Results show that WLU presents the smallest marginal costs for all airports, while ATM has the largest. Returns to scale are not exhausted at any level of production and even the largest airport exhibits increasing returns to scale, which suggests the need to increase their scale of production. However, it is worth mentioning that the air traffic management costs have not been included in the analysis. The added complexity of the traffic management task might offset some of the apparent returns to scale of the airport itself. This result could also be limited by negative externalities such as noise and congestion which have not been considered in the analysis. Evidence of significant technological progress is also obtained, especially related with the labor factor. Very limited possibilities for input substitution and elastic production factor demands have also been found.

As returns to scale are present, marginal cost pricing policies could not be applied without public subsidies or cross-subsidies from commercial activities. Clear increasing returns to scale for the airports of the sample do suggest that multiple airport systems such as those existing in London, Paris, Rome or Chicago do not have economic justification. Note that airport competition is exerted in a regional area when they try to attract airlines which establish hub operations in their facilities.

The paper also has some caveats and shortcomings. There still exists some important heterogeneity of the airports included in the sample which could be mitigated by identifying those airports that are clearly outliers. Capital and materials prices should be more related to production factors than to products. Finally, as any other economic activity, airport provision can also be subject to inefficient behavior. Therefore, other methodologies that take into account the existence of inefficiency in airport operations should be estimated to compare the results to those of this paper.

\section{Endnotes}

1. Tolofari et al. (1990) argued that all these separate estimations would result in biased estimates because the error terms are likely to be correlated, failing to adequately model this issue.

2. They categorized expenses into total, capital, maintenance, labor, administrative, and operating costs. Also, they included investments in development and air traffic control services in the cost figures. 
International Airports

3. Doganis (1992) proposed this measure to compare the output of airports. However, regarding the estimation of marginal costs a further decomposition of this variable could be an object of future research. This issue can be empirically addressed, and the marginal costs of an additional passenger could be different from one additional package of $100 \mathrm{~kg}$.

4. As he mentions, an important shortcoming of this approach is that he uses consumer rather than producer prices.

5. These figures are comparable with those obtained by Morrison (1983). €32.97 (adjusted for 2000 euros).

6. C must be nonnegative, real valued, nondecreasing and strictly positive for output; linearly homogeneous and concave in $\omega$ for each $Y$ (Shephard 1953).

7. It is necessary to drop one equation in order to avoid singularity of the disturbance covariance matrix.

8. Neutrality implies that technological change does not alter factor proportions or factor cost shares.

9. A wide-body aircraft has a fuselage diameter of about five to six meters. Passengers are usually seated seven to 10 abreast in a normal configuration of two aisles (up to 600 passengers). A traditional narrow-body aircraft has a diameter of three to four meters, a single aisle, and seats arranged from four to six abreast (up to 280 passengers).

10. CAA (2001) provides an interesting estimation of the cost difference: international peak passenger costs at Heathrow were $£ 25.69$ - $£ 29.52$ while off-peaks were $£ 0.76-£ 0.92$ (in 1982/83 prices).

11. This normalization process has been carried out for all the variables but time which has not been logged and has been transformed with respect to the nominal average.

12. The second order interaction between time and the rest of the variables were checked in a first estimation, but the final estimation of the Table 4 was obtained including only the parameters that were significant. Thus, it can be seen the interaction with time was significant for labor and capital for the single-product case, but it was significant only for labor for the multiproduct case.

Effects of technical change on input demand can be seen from the elasticities of production factors with respect to time. This elasticity is negative for labor, indicating that exogenous technical progress reduced demand for Labor by 0.4 percentage points per year. In other words, technical progress is labor saving. This result is probably explained by the use of outsourcing practices. The rising popularity in the use of outsourcing stems from the advantages that outsourcing could provide to airport operators. Airports, by outsourcing their non-core services, are able to focus more attention on their core competence.

13. Due to the logarithmic transformation, the result is obtained using the sample's geometric mean (8,494,444 passengers; 144,323 ATM; 118,891 tons of cargo).

14. The kernel density plot shows an estimate of the underlying density function. It can be considered a refinement of a histogram or frequency plot. 


\section{References}

Civil Aviation Authority (UK), Peak Pricing and Economic Regulation. Annex to CAA (2001), Heathrow, Gatwick, Stansted, and Manchester Airports Price Caps - 2003-2008: CAA Preliminary Proposals - Consultation Paper, London, www.caa.co.uk. 2001.

Christensen, L. R., D. W. Jorgenson, and L. Lau. "Transcendental Logarithmic. Production Frontiers." Review of Economics and Statistics 55(1), (1973): 28-45.

Diewert, W. E. “An Application of the Shephard Duality Theorem: A Generalized Leontieff Production Function.” Journal of Political Economy 79, (1971): 481-507.

Doganis, R. S. The Airport Business. Routledge, London, 1992.

Doganis, R. S. and G. F. Thompson. The Economics of British Airports. Transport Studies Group, 1973.

Doganis, R. S. and G. F. Thompson. "Establishing Airport Cost and Revenue Functions." The Aeronautical Journal 78, (1974): 285-304.

FAA, Compliance Activity Tracking System, 2006. http://cats.airports.faa.gov/.

IATA, ACI, ATAG, Airport Capacity and Demand Profiles, 2003.

ICAO, Airport Economics Manual. Doc 9562, 2006.

ICAO, Air Transport Industry Statistical Data 1992-2004, 2004. www.icaodata.com.

Jara-Díaz, S. R. "Freight Transportation Multioutput Analysis.” Transportation Research 17A(6), (1983): 429-438.

Jeong, J. "An Investigation of Operating Cost of Airports: Focus on the Effect of Output Scale." Dissertation (MsC). University of British Columbia, 2005.

Keeler, T. “Airport Costs and Congestion.” The American Economist 14, (1970): 47-53.

Link, H. and J.E. Nilsson. "Marginal Infrastructure Costs.” C. Nash and B. Matthews eds. Measuring the Marginal Social Costs of Transport. Oxford: Series Research in Transportation Economics, Elsevier (2005): 49-84.

Link, H., W. Götze, and V. Himanen. Estimating the Marginal Costs of Airport Operation by Using Multivariate Time Series with Correlated Error Terms. Insttitut für Verkehrswissenschaft. Diskussionspapier Nr 11, Berlin , 2006.

Main, B. G. M., B. Lever, and J. Crook. Central Scotland Airport Study, Report. The David Hume Institute, Edinburgh, 2003.

Morrison, S. A. "Estimation of Long-Run Prices and Investment Levels for Airport Runways." T.E. Keeler ed. Research in Transportation Economics I. Greenwich, CT: JAI Press, (1983): $103-130$.

Oum, T. O. and W.G. Waters. "A Survey of Recent Developments in Transportation Cost Function Research." Logistics and Transportation Review 32, (1996): 423-463. 
Oum, T. H. and C. Yu. "Measuring Airports' Operating Efficiency: A Summary of the 2003 ATRS Global Airport Benchmarking Report.” Transportation Research Part E 40, (2004): 515-532.

Rendeiro, R. "An Approximation to the Productive Efficiency of the Spanish Airports Network Through a Deterministic Cost Frontier." Journal of Air Transport Management 8, (2002): 233-238.

Shephard, R.W. Theory of Cost and Production Functions. Princeton University Press, Princeton, New Jersey, 1953.

Stevenson, R. "Measuring Technological Bias." American Economic Review 70(1), (1980): 162-173.

Tolofari, S., N. J. Ashford, and R E. Caves. The Cost of Air Service Fragmentation. Department of Transport Technology, University of Loughborough, 1990.

Wikipedia, the free encyclopedia. http: \www.wikipedia.org.

Zellner, A. "An Efficient Method of Estimating Seemingly Unrelated Regressions and Test of Aggregation Bias." Journal of the American Statistical Association 57, (1962): 348-368.

\section{Acknowledgements}

This paper draws on some results from a case study prepared for the EU Commission (research project Generalization of Research on Accounts and Cost Estimation (GRACE)). We acknowledge support under the Sustainable Surface Transport Priority Programme of the sixth FP for RTD. We want to express our gratitude to our colleagues C. A. Nash, H. Link, and E. Van de Voorde for helpful comments on an earlier draft. We also thank two anonymous referees and the editor for helpful comments and suggestions. The usual disclaimer applies. This paper has been written while Professor Martín was visiting the Institute of Transportation Studies at the University of California Berkeley. He wishes to thank Samer Madanat and Mark Hansen for being considerate hosts during his stay.

Juan Carlos Martín has a Ph.D. in economics from the University of Las Palmas de Gran Canaria (ULPGC) and is a graduate in mathematics at the Universidad Autonoma de Madrid. He is an associate professor of microeconomics at the ULPGC. His recent research is in the field of airports' efficiency, estimation of cost functions, demand analysis, and hub-and-spoke networks. He is currently leading two research projects on air transport for the European Commission.

Augusto Voltes-Dorta is a graduate in economics and business administration at the University of Las Palmas de Gran Canaria (ULPGC). He is a junior researcher at the ULPGC. His recent research is in the field of airports' efficiency, estimation of cost functions and hub-and-spoke networks. He is a doctoral student writing his PhD dissertation in the field of airports' cost functions. 